\title{
Taurine Reduced Epidural Fibrosis in Rat Models after Laminectomy via Downregulating EGR1
}

\author{
Lei Yang $^{\text {a Jian Tang }}{ }^{\mathrm{a}}$ Hongtao Chen ${ }^{\mathrm{a}}$ Dawei Ge ${ }^{\mathrm{a}}$ Tao Sui ${ }^{\mathrm{a}} \quad$ Jun Que \\ Xiaojian $\mathrm{Cao}^{\mathrm{a}}$ Yingbin $\mathrm{Ge}^{\mathrm{b}}$ \\ aDepartment of Orthopedics, the First Affiliated Hospital of Nanjing Medical University, Nanjing, \\ ${ }^{b}$ Department of Physiology, Nanjing Medical University, Nanjing, 'Department of Intensive Care Unit, \\ the First Affiliated Hospital of Nanjing Medical University, Nanjing, China
}

\section{Kew Words}

Epidural fibrosis • Taurine $\cdot$ EGR1 • Fibroblasts • Laminectomy

\begin{abstract}
Background/Aims: Epidural fibrosis, a common complication after laminectomy, has been demonstrated to be closely associated with poor surgical outcomes. Previous studies showed that taurine had remarkable anti-fibrotic effects on lung and liver fibrosis. We performed this study to investigate the effects of taurine in rat models of epidural fibrosis after laminectomy and to explore the potential molecular mechanism. Methods: Laminectomy was performed on each rat to establish epidural fibrosis model. After taurine treatment, Masson's trichrome and immunohistochemistry staining were used to examine epidural fibrosis. Cell viability was determined using the Cell Counting Kit-8 assay. Annexin V/Propidium Iodide double staining was performed to detect fibroblasts apoptosis. Microarray was adopted to identify significantly changed mRNAs. mRNA expression was measured by qRT-PCR. Lentivirus infection was performed to establish stable knockdown and overexpression cell lines. The expression of fibrosis-related proteins was determined via Western blot. Results: Taurine treatment markedly reduced laminectomy-induced epidural fibrosis in rat models. However, this effect of taurine was independent on TGF- $\beta / S$ mad pathway, evidenced by no change in the expression of TGF- $\beta$ and its receptors. Besides, taurine had almost no effect on cell apoptosis. Interestingly, taurine treatment significantly decreased expression of EGR1 (Early growth response protein 1), an enhancer of fibrosis, both in vivo and in vitro. Furthermore, overexpression of EGR1 increased activation of fibroblasts, while EGR1 knockdown achieved an opposite effect, indicating that EGR1 plays a key role in the inhibitory effect of taurine on TGF$\beta$-induced fibrosis. Conclusions: Reduced epidural fibrosis in vivo and decreased activation of fibroblasts in vitro after taurine treatment was mediated by EGR1. Taurine promises to be a potential prevention for epidural fibrosis after laminectomy.

L. Yang and J. Tang contributed to the work equally.

Yingbin Ge

KARGER
Department of Physiology, Nanjing Medical University, 140 Hanzhong Road, Nanjing, Jiangsu province, 210029, (China)

Tel. +86 13390903583, Fax +86-25-86862022, E-Mail ybge@njmu.edu.cn 


\section{Cellular Physiology Cell Physiol Biochem 2016;38:2261-2271 and Biochemistry Published online: May 19, $2016 \quad$\begin{tabular}{l|l} 
DOI: 10.1159/00445581 2016 The Author(s). Published by S. Karger AG, Basel \\
www.karger.com/cpb
\end{tabular} \\ Yang et al.: Taurine Reduces Epidural Fibrosis}

\section{Introduction}

Epidural fibrosis (EF), a common complication after laminectomy, is the development of the deposition of dense scar tissue adjacent to the dura matter, which may extend into the neural canal and adhere to the dura mater and nerve roots with leading failed back surgery syndrome (FBSS) [1-3]. Epidural fibrosis has been demonstrated to contribute to up to $5 \%$ of poor surgical outcomes following decompressive surgery [4]. Given this, during the past decades, there has been an increasing interest in development of effective drugs to prevent the formation and adherence of the tissue to the neural elements is of importance in improving surgical outcomes.

To date, a variety of biological and non-biological agents have been adopted in preventing EF formation, such as nonsteroidal anti-inflammatory drugs [5], Mitomycin $\mathrm{C}$ (MMC) [6-8], FK506 [9], etc. Although some exerted satisfactory effects, side effects of these agents hindered further clinical application [10-12]. So there is an urgent need to seek for an alternative agent with low toxicity to solve this problem.

Taurine (2-aminoethane- sulfonic acid), a sulfur-containing amino acid, is commonly present in many energy soft drinks as well as in supplement cocktails for athletes with its claimed effects as energizer and anti-fatigue [13-15]. Naturally, the toxicity of taurine has been confirmed to be relatively low with respect to other active ingredients $[16,17]$. Taurine is not involved in protein synthesis, however, plays a vital role in the modulation of multiple intracellular physiological processes such as calcium homeostasis, cell volume regulation, etc. $[13,14]$.

Previous studies have reported that taurine exerts functions of antioxidant, antiinflammatory, and anti-apoptotic in different tissues $[18,19]$. Recently, anti-fibrotic effect of taurine in experimental lung [20] and liver [21] fibrosis has been demonstrated in a number of studies. The mechanism by which taurine ameliorates fibrosis in liver and lung was reported to be associated with decreased expression of TGF- $\beta[20,21]$.

However, no evidence to date is about whether taurine has the same anti-fibrotic effect in experimental models of epidural fibrosis after laminectomy. The purpose of the present study was to investigate the effects of taurine in rat models of epidural fibrosis after laminectomy and to explore the potential molecular mechanism.

\section{Materials and Methods}

\section{Animals and wound creation}

Eighteen male Sprague-Dawley rats, weighing 200 to 220 g, were obtained from the animal center of Nanjing Medical University and received care in compliance with the principles of International Laboratory Animal Care and the protocol was approved by the Animal Care and Research Committee of Nanjing Medical University. A total laminectomy of L1 was performed according to the procedure in the previous studies $[22,23]$. After anesthesia by intraperitoneal injection of ketamine, the L1 vertebral plate was exposed by a midline skin incision. The dura mater was exposed after removing the spinous process and vertebral plate of L1. The muscles and skin were sewed in layers. At the end of 21 days, the animals were sacrificed with a high dose of ether.

Taurine treatment in animals

The animals were randomly divided into three groups $(n=6)$ with laminectomy -induced wounds. One group was treated with intraperitoneal injection with taurine in a dose of $100 \mathrm{mg} / \mathrm{kg}$ and the other group was treated with taurine gel, and the control group which received no treatment and had only daily debridement of the wound with distilled water [24]. Treatments were carried out every 24 hours for 21 days starting from the day laminectomy were performed. Taurine was supplied by Sigma-Aldrich ${ }^{\text {TM }}$ (St Quentin Fallavier, France). To facilitate the application of the agent, we provided 5\% Taurine gel, a concentration that was assigned according to a previously study [24], by dissolving $5 \mathrm{~g}$ Taurine in $2 \mathrm{ml}$ distilled water, and then transferred the solution into $2 \%$ carboxymethylcellulose (CMC) (dissolved in distilled water) for 


\section{Cellular Physiology Cell Physiol Biochem 2016;38:2261-2271

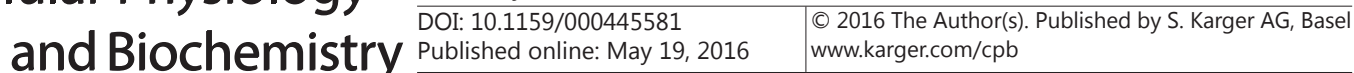 \\ Yang et al.: Taurine Reduces Epidural Fibrosis}

the topical Taurine-treated group. 5\% Taurine solution (dissolved in distilled water) was prepared for the injected taurine treated group. The CMC gel itself was administered on the laminectomy wounds and made no significant difference according to the stereological parameters, when compared with the non-treated group.

\section{Cell culture and taurine treatment}

The primary fibroblast cells were obtained from epidural scar tissue isolated from rats suffered laminectomy. Rat fibroblasts were cultured in Dulbecco's modified Eagle's medium (DMEM Invitrogen, CA, USA) supplemented with $10 \%$ fetal bovine serum (FBS), $0.1 \mathrm{U} / \mathrm{L}$ penicillin, and $50 \mu \mathrm{g} / \mathrm{mL}$ streptomycin (Gibco, CA, USA) at $37^{\circ} \mathrm{C}$ in $5 \% \mathrm{CO}_{2}$. Cells of passages 3-6 were used for all experiments. Taurine was dissolved in Dimethyl sulfoxide (DMSO) and then Phosphate buffered saline (PBS) to obtain the various concentrations of the compound. The final concentration of DMSO should have exceeded by $0.2 \%$ to avoid affecting cell viability. After approximate $80 \%$ confluence, the cells were starved overnight and then treated with TGF- $\beta 1$ ( $2 \mathrm{ng} / \mathrm{ml}$ ) (R\&D Systems, Minneapolis, MN) or Taurine in various concentrations $(10 \mu \mathrm{M}-100$ $\mathrm{mM}$ ) as indicated in the figure legends.

\section{Annexin V/Propidium Iodide Double Staining}

Annexin V/Propidium iodide double staining was used to detect the cell apoptosis. Fibroblasts were plated in 60-mm dishes ( $4 \mathrm{ml}, 1 \times 10^{6} /$ well) and incubated for 24 hours. After treatment with different concentrations of taurine, the detached and adherent cells were collected at indicated time points (24h and 48h) and washed twice with ice-cold PBS. The cells were then resuspended in binding buffer at a concentration of $1 \times 10^{6}$ cells $/ \mathrm{ml}$ and incubated with Annexin V-FITC and propidium iodide to achieve double staining according to the manufacturer's instructions. The mixture was incubated in the dark for 15 minutes at room temperature and analyzed using the Beckman Coulter FC500 flow cytometry system and CXP software (Beckman Coulter, Fullerton, CA). The cells shown in the bottom right quadrant were Annexin V-FITC positive and propidium iodide negative, indicating an early stage of apoptosis. The cells in the top right quadrant stained positively for Annexin V-FITC and propidium iodide, indicating that they consisted of secondary late apoptotic cells. The cells in the bottom left quadrant indicating normal cells, while the up left quadrant indicating death cells. The apoptosis rate in this study represents the total apoptosis rate, including early apoptosis rate and late apoptosis rate.

\section{Cell viability assay}

Cell viability was measured in a 96-well plate using a quantitative colorimetric assay with counting kit-8 (CCK-8) assay kit (Dojindo, Kumamoto, Japan). Cells were seeded in 96-well plates in triplicate, and various treatments were applied to the wells. After these treatments, the CCK-8 solution $(10 \mu \mathrm{L})$ was added to each well, and the wells were incubated for another $2 \mathrm{~h}$ at $37^{\circ} \mathrm{C}$. Absorbance was measured at $450 \mathrm{~nm}$ (Bio-Tek, Elx800, USA).

Masson staining and immunohistochemistry

A full-thickness circular skin sample with a $1 \mathrm{~cm}$ margin around the wound area was removed from the wound's site and fixed in buffered 4\% formaldehyde and then embedded in paraffin for Masson trichrome immunohistochemistry (IHC). The sections ( $5 \mu \mathrm{m}$ thick) were cut and deparaffinized in xylene, dehydrated in gradient ethanol, and then washed with PBS. The Masson trichrome staining was performed with routine protocol. For immunohistochemistry, after heat-induced epitope retrieval with $10 \mathrm{mM}$ citrate buffer (pH 6.0) by microwave oven for $15 \mathrm{~min}$, the sections were pretreated with $3 \% \mathrm{H}_{2} \mathrm{O}_{2}$ in PBS for 15 min and blocking with $5 \%$ goat serum at room temperature. Sections were incubated with rabbit anti- collagen III (Santa Cruz Biotechnology, Texas, USA), EGR1 (1:100, Protein Group, Chicago, IL, USA) or rabbit anti- $\alpha$-SMA (1:200, Abcam, Cambridge, UK) overnight at $4^{\circ} \mathrm{C}$. After the primary antibody reaction, an immunohistochemical staining kit (DAKO, CA, USA) was used. The sections were washed and stained with 3,3'-diaminobenzidine (DAB) and then counterstained with hematoxylin.

\section{Western blot analysis}

Total protein was extracted from epidural scar tissues and treated fibroblasts with RIPA buffer, and the protein concentrations were examined by the BCA method. Then $30 \mu \mathrm{g}$ proteins was separated by SDS- 


\section{Cellular Physiology Cell Physiol Biochem 2016;38:2261-2271 \begin{tabular}{l|l} 
and Biochemistry Published online: May 19, 2016 & $\begin{array}{l}\text { D } 2016 \text { The Author(s). Published by S. Karger AG, Basel } \\
\text { www.karger.com/cpb }\end{array}$ \\
\hline
\end{tabular} \\ Yang et al.: Taurine Reduces Epidural Fibrosis}

PAGE gels and transferred to polyvinylidene fluoride (PVDF) membrane (Millipore, Billerica, MA, U.S.). After blocking with $5 \%$ non-fat dry milk, the membranes were incubated with primary antibodies. The primary antibodies were used as followed: p-Smad2/3, Smad2/3, GAPDH (1:1000, Cell Signaling Technology, Boston USA), $\alpha$-SMA (Abcam, Cambridge, UK), Collagen III, TGF- $\beta 1$, TGF $\beta R I$, TGF $\beta R I I$, Smad7 (1:500, Santa Cruz Biotechnology, Texas, USA), EGR1 (1:200, Protein Group, Chicago, IL, USA). Horseradish peroxidase (HRP)conjugated secondary antibody (1:5000, Santa Cruz Biotechnology, Texas, USA) and ECL detection reagents (Millipore, Billerica, MA) were used for luminochemical detection. Images were quantified by densitometry. The results were normalized to GAPDH. All experiments were carried out 3 times.

\section{RNA preparation and quantitative real-time PCR}

Total RNA in epidural scar tissues and treated fibroblasts were isolated using TRIzol reagent (Invitrogen, Carlsbad, CA, USA) according to the manufacturer's instructions. RT was performed using the RevertAidTM First Strand cDNA Synthesis Kit (Fermentas, Ottawa, Canada) following the manufacturer's instructions. The random RT primer 5'- (dN) 9-3' was used for EGR1, and GAPDH genes. The polymerase chain reaction (PCR) primers were designed using an S ABI SYBR Green Master Mix (Invitrogen) according to the manufacturer's protocol. Detailed primers were as follows: EGR1: Sense: $5^{\prime}$-AGA AGG ACA AGA AAG CAG ACA AAA GTGT-3'; Antisense: 5'-GGG GAC GGG TAG GAA GAGAG-3', GAPDH: Sense: 5'-TGC ACC ACC AAC TGC TTAGC-3'; Antisense: 5'- GGC ATG GAC TGT GGT CAT GAG-3'. All mRNA quantification data were normalized to GAPDH as an endogenous control for the mRNA detection. The data were processed using $2^{-\Delta \Delta \mathrm{Ct}}$ methods.

Microarray data generation and analysis

Total RNAs were extracted using the TRizol reagent (Invitrogen, Carlsbad, CA, USA) from fibroblasts treated with TGF- $\beta$ (triplicate) and TGF- $\beta+$ Taurine (triplicate). cDNAs were generated, fragmented, biotinylated, and hybridized to the Agilent Rat MicroRNA Microarray V3 Technology platform, which completed by Shanghai Huaying Biological Co., Ltd. (Huaying, Shanghai, China) according to the vendor's protocol.

\section{Cell infection}

To establish stable knockdown and overexpression cell lines, the lentivirus vectors pLV-EGR1-inhibitor (target sequences: Sense: 5'-AGUUUGCCAGGAGCGAUGA-3' Antisense: 5'-UCAUCGCUCCUGGCAAACU-3') [25] and pLV-EGR1-overexpression (NM_001964), along with the packaging plasmid mix, were purchased from Shanghai GenePharma Co., Ltd (Shanghai, China). Individual plasmids and the packaging mix were co-transfected into HEK293TN packaging cell lines using Lipofectamine2000. The culture supernatant was concentrated using the Lenti-pac lentivirus concentration solution (Genecopoeia, Guangzhou, China). The control plasmid provided with the lentivirus kit was processed as described above to obtain the control pseudovirus (sequence: 5' GTCCCGGATACCTAATAAA 3'). Fibroblasts were incubated with the lentiviruses in the presence of $2 \mu \mathrm{g} / \mathrm{mL}$ polybrene (Gibco, CA, USA) and were cultured with $2 \mu \mathrm{g} / \mathrm{mL}$ puromycin (Sigma, CA, USA) for at least $96 \mathrm{~h}$ to select the stably transfected cells.

\section{Statistical analysis}

The data were collected, analyzed, and reported as mean and standard deviation (mean \pm SD). Besides, the statistical comparisons between the groups were carried out by the SPSS statistical software (v. 17.0). The statistical differences among different groups were analyzed by Student's t-test. P $\leq 0.05$ was considered to be statistically significant.

\section{Results}

Taurine treatment reduced laminectomy-induced epidural fibrosis in rats

To first investigate the effects of taurine in vivo, we performed laminectomy on all rats to induce epidural fibrosis. Then the rats were intraperitoneal injected or topical administrated with taurine, and untreated rats were served as control. To choose proper dose, rats were administrated with taurine at different concentrations: 50, 100, 150 and 


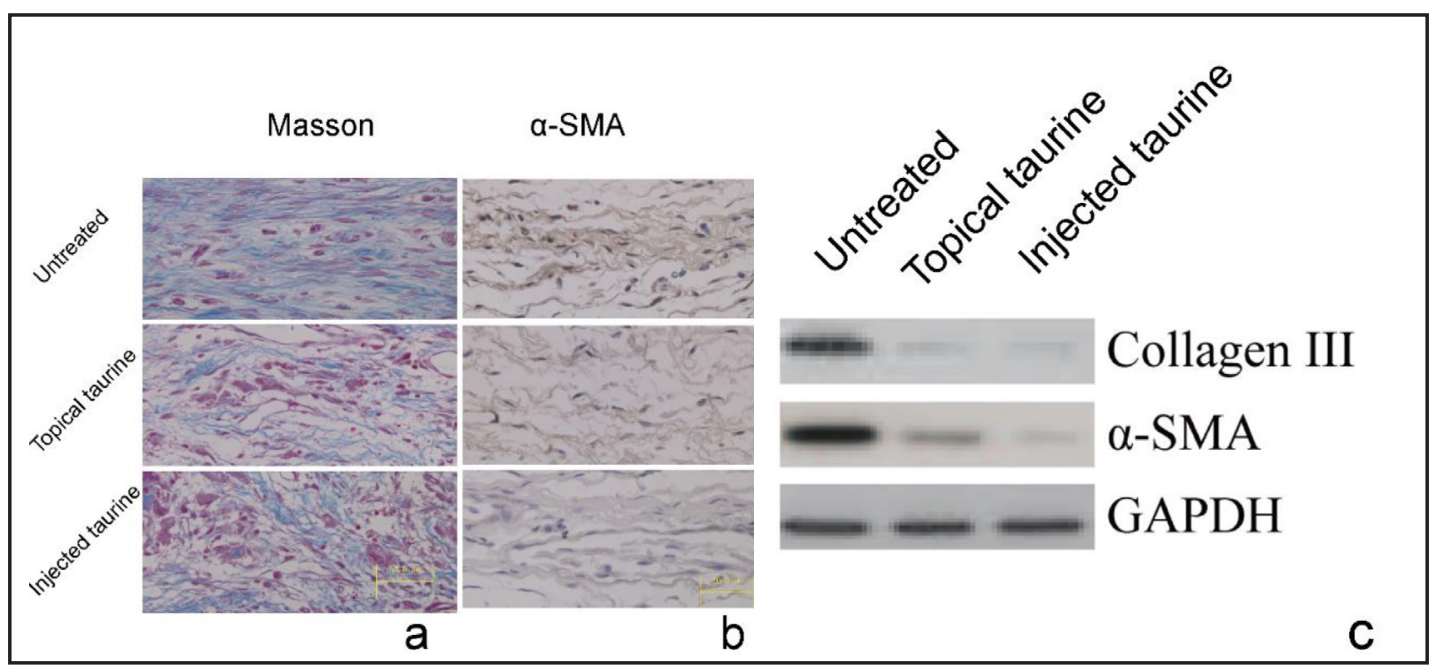

Fig. 1. Taurine treatment reduced epidural fibrosis in rats after laminectomy. (a) Masson's trichrome staining for epidural adhesion in the laminectomy sites; (b) Western blotting for expression of $\alpha$-SMA and Collagen III.

Fig. 2. Taurine-mediated attenuation of epidural fibrosis is independent on TGF $\beta$-Smad pathway: Western blotting for expression of markers in TGF- $\beta$ / Smad signaling pathway.

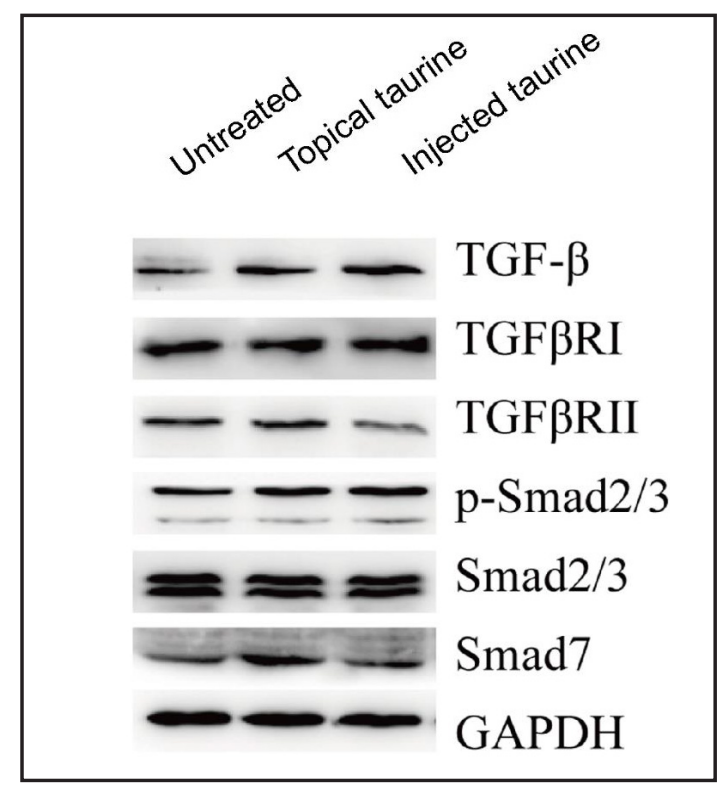

$200 \mathrm{mg} / \mathrm{kg}$. We found that administration of taurine at the dose of $50 \mathrm{mg} / \mathrm{kg}$ did not exhibit remarkable improvement in reducing epidural adhesion, while $100 \mathrm{mg} / \mathrm{kg}$ resulted in significant effects. Given this, we chose the dose of $100 \mathrm{mg} / \mathrm{kg}$ for further experiments in vivo. For all rats, Masson's trichrome staining showed that laminectomy induced extensive epidural fibrosis. Compared to control, the rats treated with either topical or injected taurine exhibited significantly ameliorated epidural fibrosis (Fig. 1a). In addition, expression of $\alpha$-SMA, a marker of fibroblasts activation $[25,26]$, analyzed by immunohistochemistry and western blot confirmed the results of Masson's trichrome staining (Fig. 1b and c). Moreover, the expression of collagen III, which plays an important role in fibrosis [27], also reduced in taurine treated rats (Fig. 1c). These results indicated that taurine treatment could significantly reduce epidural fibrosis in vivo.

Taurine-mediated attenuation of laminectomy-induced epidural fibrosis was not dependent on TGF- $\beta /$ Smad pathway

To examine whether the effects of taurine were dependent on TGF- $\beta$ / Smad signaling pathway, which was demonstrated to be closely associated with fibrogenesis $[28,29]$, we 


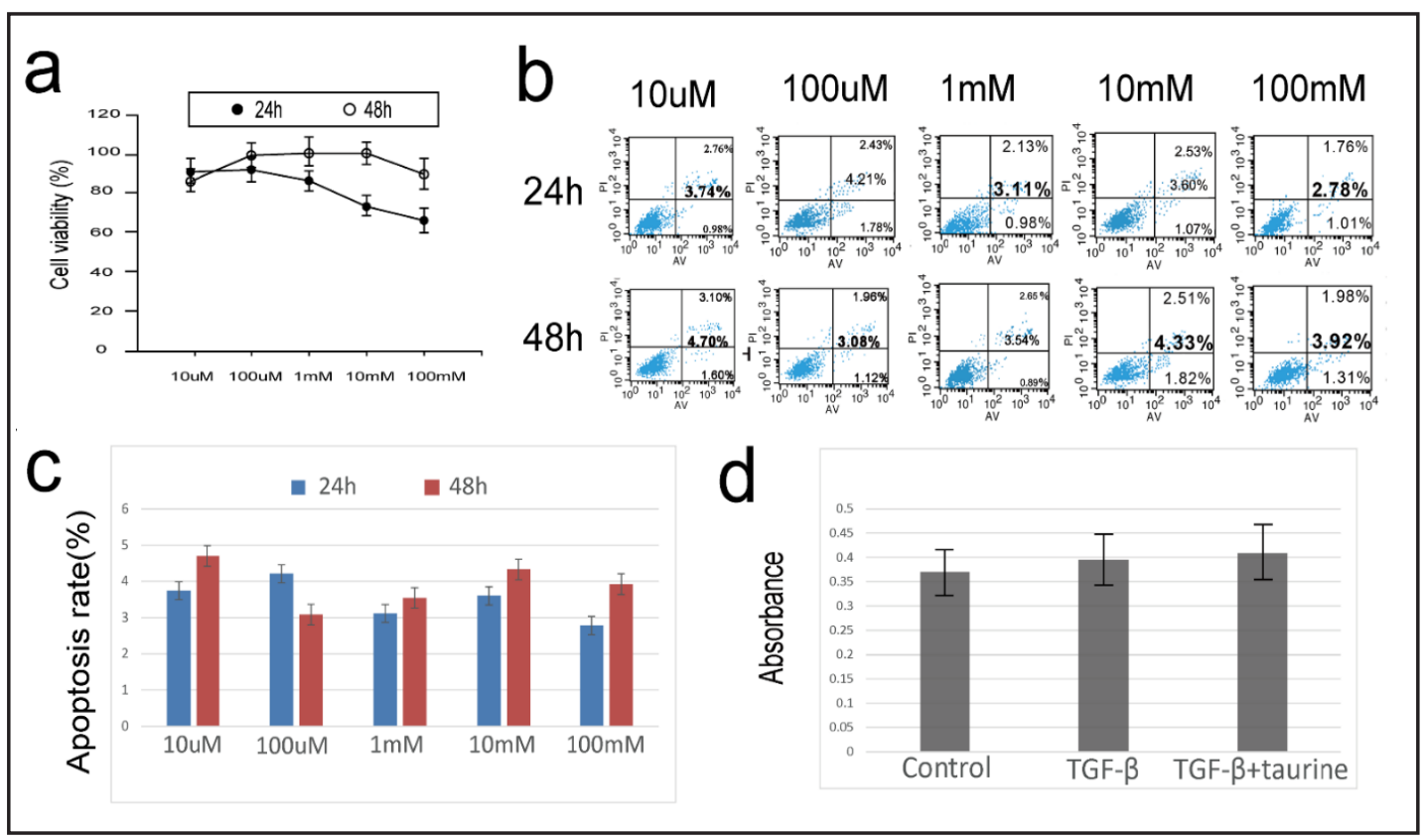

Fig. 3. Taurine treatment had no significant effect on cell viability of fibroblasts. (a) Cell viability of fibroblasts after treatment with taurine at various concentrations (10 uM, $100 \mathrm{uM}, 1 \mathrm{mM}, 10 \mathrm{mM}$ and $100 \mathrm{mM})$ for $24 \mathrm{~h}$ or $48 \mathrm{~h}$ was detected by CCK-8 assay; (b-c) Cell apoptosis was detected by Flow Cytometry at the indicated time points (24 and 48 hours) after treatment with various concentrations of Taurine (10 uM, $100 \mathrm{uM}$, $1 \mathrm{mM}, 10 \mathrm{mM}$ and $100 \mathrm{mM}$ ). (d) CCK-8 assay showed absorbance of fibroblasts at $450 \mathrm{~nm}$ after treatment with control, TGF- $\beta$ or a combination of TGF- $\beta$ and taurine (10 mM) for $48 \mathrm{~h}$.

explored the expression of key markers in this pathway. Compared to those untreated rats, no significant change of the expression of TGF- $\beta 1$ and its receptors (TGF- $\beta$ RI, TGF- $\beta$ RII) was found in neither topical nor injected taurine treated animals. In addition, expression of neither p-Smad2/3 (activated Smad2/3) nor Smad 7 markedly altered after taurine treatment (Fig. 2). These results suggested that taurine-mediated attenuation of laminectomy-induced epidural fibrosis was not dependent on TGF- $\beta /$ Smad pathway.

\section{Taurine had no significant effect on cell apoptosis}

Given that only if osmolarity change due to taurine administration was more than 737 mOsm, cell viability altered significantly, we did not carried on experiments in equimolar sucrose or similar osmolyte as control [30,31]. According to the results from a CCK-8 assay, fibroblasts treated with up to $100 \mathrm{mM}$ taurine for $48 \mathrm{~h}$ exhibited no significant reduction of cell viability (Fig. 3a). Annexin V/Propidium Iodide double staining results also showed that fibroblasts treated with up to $100 \mathrm{mM}$ taurine for $24 \mathrm{~h}$ or $48 \mathrm{~h}$ exhibited no significant apoptosis (Fig. 3b and 3c). Moreover, CCK-8 assay suggested that, even after pretreatment with TGF- $\beta$, additional administration of taurine $(10 \mathrm{mM})$ had not yet markedly changed cell viability of the fibroblasts (Fig. $3 \mathrm{~d}$ ). These results indicated that the inhibitory effects of taurine were not dependent on regulation of fibroblasts apoptosis.

Taurine decreased expression of EGR1 both in vivo and in vitro

To figure out the potential molecular mechanism, we performed mRNA microarray.

According to the results, expressions of 16 genes were significantly altered (more than 2-fold), including 1 decreased and 15 increased mRNAs (Fig. 4a). Then, through bioinformatics analysis, correlation of fibrosis with the 15 increased mRNAs was not reported to date. Interestingly, the decreased mRNA 'early growth response (EGR1)' was reported to be closely related to fibrosis in many previous studies [32-35]. Therefore, we 


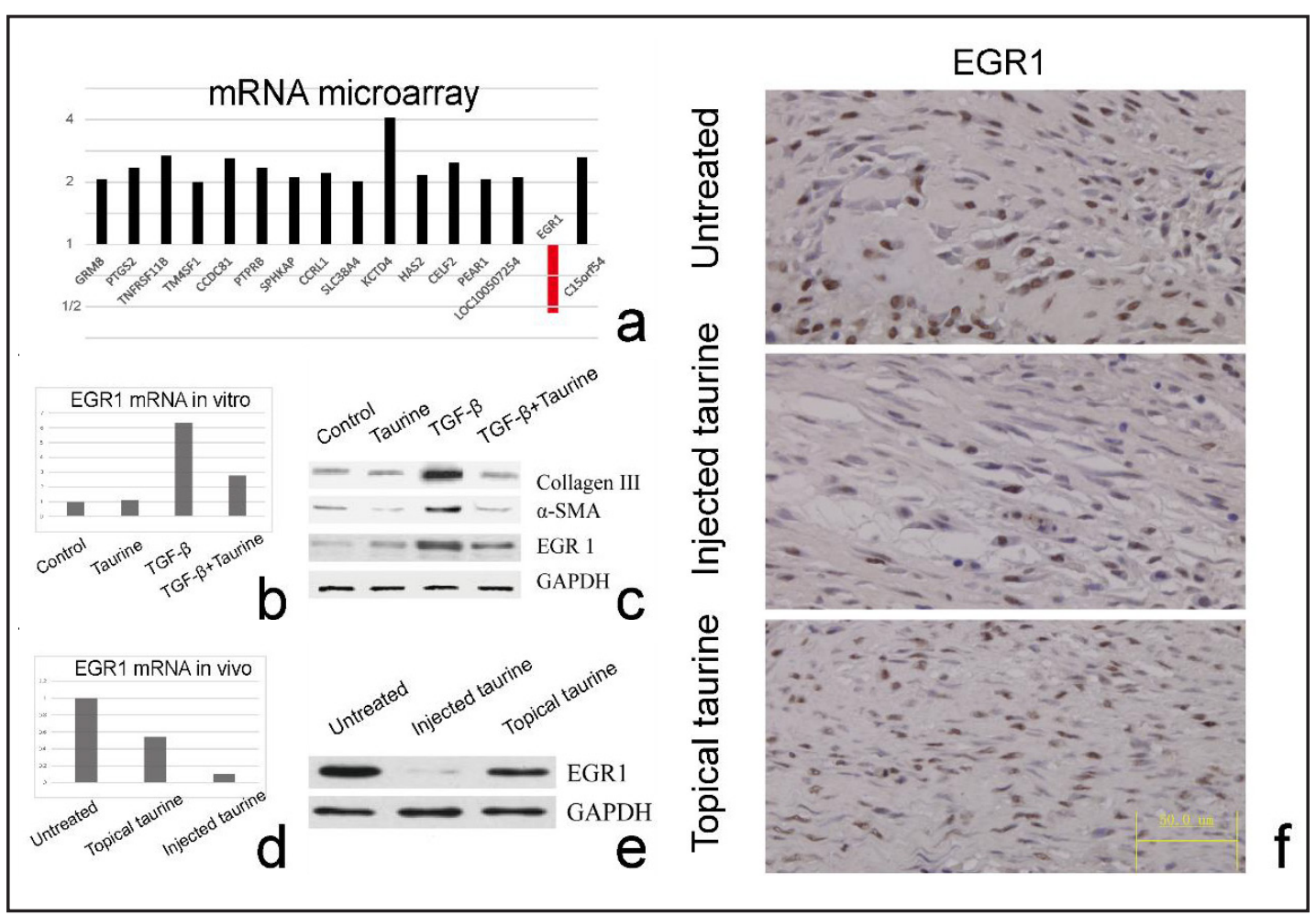

Fig. 4. Expression of EGR1 was reduced after taurine treatment both in vivo and in vitro. (a) mRNA microarray showed significantly changed mRNAs ( $>2$-fold), among, EGR1 was the only significantly decreased mRNA after taurine treatment; (b) EGR1 mRNA level was validated in vitro; (c) Protein levels of EGR1, $\alpha$-SMA and Collagen III in vitro were determined by Western blot. (d) EGR1 mRNA level was validated in vivo; (e) Protein level of EGR1 in vitro was detected by Western blot; (f) The expression of EGR1 was assayed by immunohistochemical staining.

focused on EGR1 in the further experiments. Then we performed Western blot, qRT-PCR and IHC staining to validate the above results. Results in vitro showed that TGF- $\beta 1$ markedly enhanced expression of $\alpha$-SMA and collagen III in fibroblasts and meanwhile significantly increased EGR1 both in mRNA and protein levels. However, this effect of TGF- $\beta 1$ can be partially reversed by taurine treatment (Fig. $4 \mathrm{~b}$ and c). Besides, experiments in vivo also demonstrated that taurine administration markedly reduced EGR1 (Fig. 4d, e and f). These results indicated that taurine treatment significantly decreased expression of EGR1 both in vivo and in vitro.

\section{EGR1 played a role in the inhibitory effect of taurine on TGF- $\beta 1$-induced fibrosis}

To further elucidate the role of EGR1 in the process of fibrosis, we generated stable cell lines using expressing EGR1 and EGR1 inhibitors or their scrambled controls with lentiviral constructs inducing or inhibiting EGR1 expression. Western blot analysis confirmed the expression levels of EGR1 in the stable cell lines (Fig. 5a). As we expected, overexpression of EGR1 resulted in increased $\alpha$-SMA in fibroblasts. In addition, the upregulated expression of $\alpha$-SMA in TGF- $\beta 1$-treated cells was partially reversed by knockdown of EGR1 (Fig. 5b).

\section{Discussion}

Epidural fibrosis, a replacement of normal epidural fat with postoperative fibrotic tissue, binds the dura and nerve roots to the surrounding structures anteriorly and posteriorly and

\section{KARGER}


Fig. 5. Knockdown of EGR1 inhibited activation of fibroblasts. (a) Effects of knockdown and overexpression of EGR1 in the cell lines were determined by Western blot; (b) Overexpression of EGR1 significantly increased expression of $\alpha$-SMA, while EGR1 knockdown had an opposite effect.

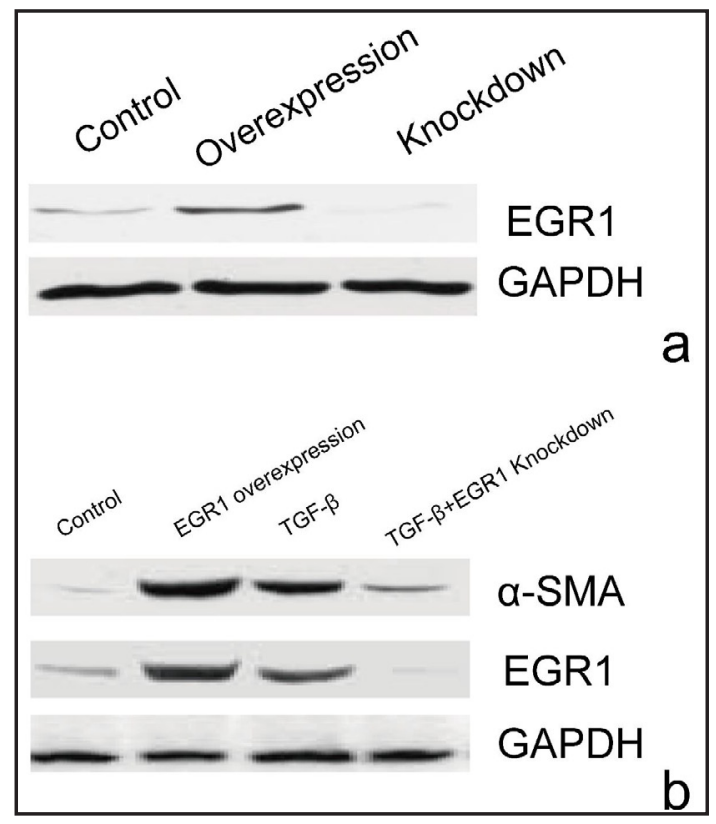

thus leads to poor outcomes in spinal surgeries [1-4]. Previous reports have showed that epidural fibrosis was closely related to fibroblasts activation and collagen overproduction [27]. In this process, $\alpha$-SMA was a critical marker of activated fibroblasts and plays essential roles in the pathogenesis of hypertrophic scars $[25,26]$. Besides, to our knowledge, an increase in production of TGF- $\beta$ is one of the most important mechanisms in the pathogenesis of fibrosis [36, 37]. TGF- $\beta$ binds to and activates specific receptors (TGF- $\beta$ RI, TGF- $\beta$ RII) and thus stimulates the phosphorylation of Smad2 and Smad3 proteins, which in turn form complexes with Smad4. The complex then translocates from cytoplasm into nucleus, where the Smads regulate the transcription of target genes, including Smad7, which negatively regulates Smad2 and Smad3 activation and inhibits fibrosis [38-41].

Taurine is previously reported to demonstrate antioxidant and anti-inflammatory effects in tissues by decreasing the lipid peroxidation and neutrophil adhesion [13-15]. Recent studies showed that taurine has crucial protective effect on liver or lung fibrosis [20, 21]. However, whether taurine can reduce epidural fibrosis remains unclear.

The present study was conducted to investigate the effects of taurine administration on fibrosis both in vivo and vitro. First we established laminectomy-induced epidural fibrosis in rat models and found that taurine administration significantly attenuated the epidural fibrosis in vivo, evidenced by downregulated expression of $\alpha$-SMA and collagen III after taurine treatment. To figure out whether the effects of taurine was dependent on TGF- $\beta$ / Smad signaling pathway, we explored the expression of TGF- $\beta$, TGF- $\beta$ receptors and Smad 2/3, phosphorylated Smad 2/3 and Smad 7. Results showed that taurine administration did not significantly alter expression of these markers, indicating that the inhibitory effects of taurine was not dependent on TGF- $\beta$ / Smad signaling pathway. In addition, cell viability assay and Annexin V/PI double staining demonstrated that the exhibited protective effects of taurine was not via regulation of fibroblast apoptosis. To further explore the cellular and molecular mechanisms of inhibitory effects of taurine on fibrosis, the difference of mRNA between TGF- $\beta$ treated with or without taurine was analyzed through microarray analysis. To our surprise, the transcription factor early growth response gene 1 (EGR1) was downregulated by taurine treatment under TGF- $\beta$-induced stimulation. EGR1 is a zinc-finger nuclear phosphoprotein and transcription factor [42], induced by environmental stress, developmental signals, cytokines, growth factors, hypoxia and oxidative stress [43, 44]. Moreover, EGR1 plays a vital functional role in profibrotic TGF- $\beta$-responses by mediating the TGF- $\beta$ stimulated collagen expression [33-35]. Further, both in vitro and in vivo experiments confirmed that taurine treatment indeed significantly reduced EGR1. To further elucidate 


\section{Cellular Physiology Cell Physiol Biochem 2016;38:2261-2271 \begin{tabular}{l|l} 
and Biochemistry Published online: May 19, 2016 & $\begin{array}{l}\text { Do 2016 The Author(s). Published by S. Karger AG, Basel } \\
\text { www.karger.com/cpb }\end{array}$ \\
\hline
\end{tabular} \\ Yang et al.: Taurine Reduces Epidural Fibrosis}

the role of EGR1 in the TGF- $\beta 1$ induced fibrosis, we generated EGR1 overexpression and EGR1 knockdown cell lines. Enforced EGR1 expression resulted in an increased expression of $\alpha$-SMA, while knockdown of EGR1 restored the increased expression of $\alpha$-SMA induced by TGF- $\beta 1$, indicating that EGR1 plays an important role in the process of fibrogenesis.

However, limitations still existed in our study. For instance, oral route was probably preferred in systemic delivery of taurine. However, the activity of rats were restricted in this laminectomy model, Thus, administration of taurine by i.p. method should be easy to control the absorption of taurine than those by oral route. On the other hand, the method of gavage would enhanced the damage in the rat spine cord. In fact, some previous studies indicated that taurine could administrate by i.p. methods [24]. For humans, oral route seemed to be more preferred. In addition, we indeed found a small reduction of cell viability at $24 \mathrm{~h}$ after taurine treatment (Fig. 3A), which we thought to be related to taurine's anti-TGF- $\beta$ effect $[45,46]$. Our previous study demonstrated that TGF- $\beta$ significantly stimulated fibroblast proliferation [47]. Therefore, we hypothesized that taurine treatment temporarily inhibited the proliferation ability induced by fibroblasts secreted TGF- $\beta$. The exact reason of this observed reduction in cell viability remained to be further explored. Besides, through the mRNA microarray, we found 16 significantly changed mRNAs, however, the 15 upregulated mRNAs were not further analyzed in the present study. We just selected EGR1 for further validation via bioinformatics databases. The inhibitory effects on fibrosis of taurine might also be attributed to these upregulated mRNAs. In our further study, we planned to make detailed investigation about the rest genes.

In summary, we examined the effects of taurine on epidural fibrosis both in vivo and in vitro in the present study and found that taurine might exhibit its effects via downregulating EGR1. To our knowledge, this is the first attempt to explore the effects and the potential mechanisms of taurine on epidural fibrosis. Based on our findings, exogenous taurine administration promises to be a potential prevention for epidural fibrosis after laminectomy.

\section{Acknowledgments}

This study was supported by National Natural Foundation of China (\#81371968, \#81371969, \#81171694, \#81401791).

\section{Disclosure Statement}

The authors declare no financial or other conflicts of interest.

\section{References}

1 Geisler FH: Prevention of peridural fibrosis: Current methodologies. Neurol Res 1999;21:S9-S22.

2 Alkalay RN, Kim DH, Urry DW, Xu J, Parker TM, Glazer PA: Prevention of postlaminectomy epidural fibrosis using bioelastic materials. Spine (Phila Pa 1976) 2003;28:1659-1665.

3 Lee CK, Alexander H: Prevention of postlaminectomy scar formation. Spine (Phila Pa 1976) 1984;9:305312.

4 Manchikanti L, Boswell MV, Rivera JJ, Pampati VS, Damron KS, McManus CD, Brandon DE, Wilson SR: [ISRCTN 16558617] a randomized, controlled trial of spinal endoscopic adhesiolysis in chronic refractory low back and lower extremity pain. BMC Anesthesiol 2005;5:10.

5 Sandoval MA, Hernandez-Vaquero D: Preventing peridural fibrosis with nonsteroidal anti-inflammatory drugs. Eur Spine J 2008;17:451-455.

6 Sun Y, Ge Y, Fu Y, Yan L, Cai J, Shi K, Cao X, Lu C: Mitomycin C induces fibroblasts apoptosis and reduces epidural fibrosis by regulating miR-200b and its targeting of RhoE. Eur J Pharmacol 2015;765:198-208. 


\section{Cellular Physiology Cell Physiol Biochem 2016;38:2261-2271 and Biochemistry Published online: May 19, $2016 \quad \begin{aligned} & \text { DOI: 10.1159/000445581 } 2016 \text { The Author(s). Published by S. Karger AG, Basel } \\ & \text { www.karger.com/cpb }\end{aligned}$ \\ Yang et al.: Taurine Reduces Epidural Fibrosis}

7 Lee JY, Stenzel W, Impekoven P, Theisohn M, Stutzer H, Lohr M, Reithmeier T, Ernestus RI, Ebel H, Klug $\mathrm{N}$ : The effect of mitomycin $\mathrm{C}$ in reducing epidural fibrosis after lumbar laminectomy in rats. J Neurosurg Spine 2006;5:53-60.

8 Lee JY, Stenzel W, Lohr M, Stutzer H, Ernestus RI, Klug N: The role of mitomycin C in reducing recurrence of epidural fibrosis after repeated operation in a laminectomy model in rats. J Neurosurg Spine 2006;4:329333.

9 Cemil B, Tun K, Kaptanoglu E, Kaymaz F, Cevirgen B, Comert A, Tekdemir I: Use of pimecrolimus to prevent epidural fibrosis in a postlaminectomy rat model. J Neurosurg Spine 2009;11:758-763.

10 Rauch MC, San MA, Ojeda D, Quezada C, Salas M, Carcamo JG, Yanez AJ, Slebe JC, Claude A: Tacrolimus causes a blockage of protein secretion which reinforces its immunosuppressive activity and also explains some of its toxic side-effects. Transpl Immunol 2009;22:72-81.

11 Kemper MJ, Sparta G, Laube GF, Miozzari M, Neuhaus TJ: Neuropsychologic side-effects of tacrolimus in pediatric renal transplantation. Clin Transplant 2003;17:130-134.

12 Veen EJ, Dikkers FG: Topical use of MMC in the upper aerodigestive tract: A review on the side effects. Eur Arch Otorhinolaryngol 2010;267:327-334.

13 Ripps H, Shen W: Review: Taurine: A "very essential" amino acid. Mol Vis 2012;18:2673-2686.

14 De Luca A, Pierno S, Camerino DC: Taurine: The appeal of a safe amino acid for skeletal muscle disorders. J Transl Med 2015;13:243.

15 Lombardini JB: Effects of ATP and taurine on calcium uptake by membrane preparations of the rat retina. J Neurochem 1983;40:402-406.

16 Ebrahim AS, Babu E, Thirunavukkarasu C, Sakthisekaran D: Protective role of vitamin E, 2-deoxy-D-glucose, and taurine on perchloroethylene induced alterations in ATPases. Drug Chem Toxicol 2001;24:429-437.

17 Zeidan-Chulia F, Gelain DP, Kolling EA, Rybarczyk-Filho JL, Ambrosi P, Terra SR, Pires AS, Da RJ, Behr GA, Moreira JC: Major components of energy drinks (caffeine, taurine, and guarana) exert cytotoxic effects on human neuronal SH-SY5Y cells by decreasing reactive oxygen species production. Oxid Med Cell Longev 2013;2013:791795.

18 Marcinkiewicz J, Kontny E: Taurine and inflammatory diseases. Amino Acids 2014;46:7-20.

19 Marcinkiewicz J, Wojas-Pelc A, Walczewska M, Lipko-Godlewska S, Jachowicz R, Maciejewska A, Bialecka A, Kasprowicz A: Topical taurine bromamine, a new candidate in the treatment of moderate inflammatory acne vulgaris: A pilot study. Eur J Dermatol 2008;18:433-439.

20 Robb WB, Condron C, Moriarty M, Walsh TN, Bouchier-Hayes DJ: Taurine attenuates radiation-induced lung fibrosis in C57/Bl6 fibrosis prone mice. Ir J Med Sci 2010;179:99-105.

21 Devi SL, Viswanathan P, Anuradha CV: Regression of liver fibrosis by taurine in rats fed alcohol: Effects on collagen accumulation, selected cytokines and stellate cell activation. Eur J Pharmacol 2010;647:161-170.

22 Lee JY, Stenzel W, Ebel H, Wedekind C, Ernestus RI, Klug N: Mitomycin C in preventing spinal epidural fibrosis in a laminectomy model in rats. J Neurosurg 2004;100:52-55.

23 Sun Y, Wang LX, Wang L, Sun SX, Cao XJ, Wang P, Feng L: A comparison of the effectiveness of mitomycin $\mathrm{C}$ and 5-fluorouracil in the prevention of peridural adhesion after laminectomy. J Neurosurg Spine 2007;7:423-428.

24 Ashkani-Esfahani S, Zarifi F, Asgari Q Samadnejad AZ, Rafiee S, Noorafshan A: Taurine improves the wound healing process in cutaneous leishmaniasis in mice model, based on stereological parameters. Adv Biomed Res 2014;3:204.

25 Song HY, Kim MY, Kim KH, Lee IH, Shin SH, Lee JS, Kim JH: Synovial fluid of patients with rheumatoid arthritis induces alpha-smooth muscle actin in human adipose tissue-derived mesenchymal stem cells through a TGF-beta1-dependent mechanism. Exp Mol Med 2010;42:565-573.

26 Hong IH, Park SJ, Goo MJ, Lee HR, Park JK, Ki MR, Kim SH, Lee EM, Kim AY, Jeong KS: JNK1 and JNK2 regulate alpha-SMA in hepatic stellate cells during CCl4 -induced fibrosis in the rat liver. Pathol Int 2013;63:483-491.

27 Pascu EI, Pisoschi CG, Andrei AM, Munteanu MC, Rauten AM, Scrieciu M, Taisescu O, SurpaTeanu M, BaniTa IM: Heterogeneity of collagen secreting cells in gingival fibrosis--an immunohistochemical assessment and a review of the literature. Rom J Morphol Embryol 2015;56:49-61.

28 Chen T, Nie H, Gao X, Yang J, Pu J, Chen Z, Cui X, Wang Y, Wang H, Jia G: Epithelial-mesenchymal transition involved in pulmonary fibrosis induced by multi-walled carbon nanotubes via TGF-beta/Smad signaling pathway. Toxicol Lett 2014;226:150-162. 


\section{Cellular Physiology Cell Physiol Biochem 2016;38:2261-2271 \begin{tabular}{l|l} 
and Biochemistry 10.1159/000445581 & $\begin{array}{l}\text { DO 2016 The Author(s). Published by S. Karger AG, Basel } \\
\text { Published online: May 19, } 2016\end{array}$ \\
\hline
\end{tabular} \\ Yang et al.: Taurine Reduces Epidural Fibrosis}

29 Wang L, Chi YF, Yuan ZT, Zhou WC, Yin PH, Zhang XM, Peng W, Cai H: Astragaloside IV inhibits renal tubulointerstitial fibrosis by blocking TGF-beta/Smad signaling pathway in vivo and in vitro. Exp Biol Med (Maywood) 2014;239:1310-1324.

30 Lambert IH, Enghoff MS, Brandi ML, Hoffmann EK: Regulation of p53 in NIH3T3 mouse fibroblasts following hyperosmotic stress. Physiol Rep DOI:10.14814/phy2.12412.

31 Benazzoug Y, Borchiellini C, Labat-Robert J, Robert L, Kern P: Effect of high-glucose concentrations on the expression of collagens and fibronectin by fibroblasts in culture. Exp Gerontol 1998;33:445-455.

32 Bhattacharyya S, Fang F, Tourtellotte W, Varga J: Egr-1: New conductor for the tissue repair orchestra directs harmony (regeneration) or cacophony (fibrosis). J Pathol 2013;229:286-297.

33 Lee CG, Cho SJ, Kang MJ, Chapoval SP, Lee PJ, Noble PW, Yehualaeshet T, Lu B, Flavell RA, Milbrandt J, Homer RJ, Elias JA: Early growth response gene 1-mediated apoptosis is essential for transforming growth factor beta1-induced pulmonary fibrosis. J Exp Med 2004;200:377-389.

34 Bhattacharyya S, Wu M, Fang F, Tourtellotte W, Feghali-Bostwick C, Varga J: Early growth response transcription factors: Key mediators of fibrosis and novel targets for anti-fibrotic therapy. Matrix Biol 2011;30:235-242.

35 Derdak Z, Villegas KA, Wands JR: Early growth response- 1 transcription factor promotes hepatic fibrosis and steatosis in long-term ethanol-fed Long-Evans rats. Liver Int 2012;32:761-770.

36 Wang R, Ghahary A, Shen Q, Scott PG, Roy K, Tredget EE: Hypertrophic scar tissues and fibroblasts produce more transforming growth factor-beta1 mRNA and protein than normal skin and cells. Wound Repair Regen 2000;8:128-137.

37 Liu J, Wang Y, Pan Q, Su Y, Zhang Z, Han J, Zhu X, Tang C, Hu D: Wnt/beta-catenin pathway forms a negative feedback loop during TGF-beta1 induced human normal skin fibroblast-to-myofibroblast transition. J Dermatol Sci 2012;65:38-49.

38 Fukasawa H, Yamamoto T, Togawa A, Ohashi N, Fujigaki Y, Oda T, Uchida C, Kitagawa K, Hattori T, Suzuki S, Kitagawa M, Hishida A: Down-regulation of Smad7 expression by ubiquitin-dependent degradation contributes to renal fibrosis in obstructive nephropathy in mice. Proc Natl Acad Sci U S A 2004;101:86878692.

39 Schnaper HW, Hayashida T, Poncelet AC: It's a Smad world: Regulation of TGF-beta signaling in the kidney. J Am Soc Nephrol 2002;13:1126-1128.

40 Ebisawa T, Fukuchi M, Murakami G, Chiba T, Tanaka K, Imamura T, Miyazono K: Smurf1 interacts with transforming growth factor-beta type I receptor through Smad7 and induces receptor degradation. J Biol Chem 2001;276:12477-12480.

41 Kavsak P, Rasmussen RK, Causing CG, Bonni S, Zhu H, Thomsen GH, Wrana JL: Smad7 binds to Smurf2 to form an E3 ubiquitin ligase that targets the TGF beta receptor for degradation. Mol Cell 2000;6:1365-1375.

42 Sukhatme VP, Cao XM, Chang LC, Tsai-Morris CH, Stamenkovich D, Ferreira PC, Cohen DR, Edwards SA, Shows TB, Curran T, Et A: A zinc finger-encoding gene coregulated with c-fos during growth and differentiation, and after cellular depolarization. Cell 1988;53:37-43.

43 Baron V, Adamson ED, Calogero A, Ragona G, Mercola D: The transcription factor Egr1 is a direct regulator of multiple tumor suppressors including TGFbeta1, PTEN, p53, and fibronectin. Cancer Gene Ther 2006;13:115-124.

44 Thiel G, Cibelli G: Regulation of life and death by the zinc finger transcription factor Egr-1. J Cell Physiol 2002;193:287-292.

45 Devi SL, Viswanathan P, Anuradha CV: Regression of liver fibrosis by taurine in rats fed alcohol: Effects on collagen accumulation, selected cytokines and stellate cell activation. Eur J Pharmacol 2010;647:161-170.

46 Kato J, Ido A, Hasuike S, Uto H, Hori T, Hayashi K, Murakami S, Terano A, Tsubouchi H: Transforming growth factor-beta-induced stimulation of formation of collagen fiber network and anti-fibrotic effect of taurine in an in vitro model of hepatic fibrosis. Hepatol Res 2004;30:34-41.

47 Tong J, Fu Y, Xu X, Fan S, Sun H, Liang Y, Xu K, Yuan Z, Ge Y: TGF-beta1 stimulates human Tenon's capsule fibroblast proliferation by miR-200b and its targeting of p27/kip1 and RND3. Invest Ophthalmol Vis Sci 2014;55:2747-2756. 